\title{
MONTEIRO LOBATO E A LITERATURA NA ESCOLA
}

\section{INTRODUÇÃO}

\author{
Claudecir dos Santos ${ }^{1}$ \\ Estelamaris Galiazzi² \\ Neila Carla Camerini ${ }^{3}$
}

Atualmente, encontramos vários escritores da literatura infantil que, fazendo uso de diversas estratégias, se preocupam em encantar as crianças (e isso se estende aos adultos), com narrativas envolventes e compreensíveis, o que, consequentemente, as tornariam prazerosas. Entretanto, envolver e tornar compreensível o que se escreve não é uma tarefa que se executa pelo simples desejo de escrever. Na verdade, são poucos aqueles e aquelas que conseguem tal feito.

Se o desafio de envolver e encantar pessoas através da leitura é grandioso, vale apena voltar-se, mesmo que seja de forma rápida, a quem se propôs enfrentar tal desafio e obteve êxito em seus propósitos. Referimo-nos ao escritor brasileiro Monteiro Lobato.

O paulista Monteiro Lobato (1882-1948), foi contista, ensaísta e tradutor. Formado em Direito, atuou na profissão como promotor público, antes de se tornar fazendeiro a partir de uma herança de família. Motivado pelo seu novo estilo de vida, Lobato passou a escrever contos para revistas e jornais, que posteriormente suscitaram sua obra prima chamada Urupês. Lobato torna-se então, conhecido pelos leitores, por trazer em suas obras, fragmentos de realidade e fantasia, que conquistaram, mais tarde, seu público infantil. Ao tornar-se escritor em uma época em que as obras brasileiras, em sua grande maioria, eram editadas na Europa, tornando o acesso a leitura uma possibilidade para poucos, talvez o tenha motivado a fundar uma editora e editar seus próprios livros.

Em determinada fase de sua vida, especialmente quando passa a dedicar-se à literatura infantil alegando estar "cansado" do público adulto, disse ele: "de escrever para marmanjos já enjoei. Bichos sem graça. Mas para as crianças um livro é todo um mundo" (LOBATO, apud COELHO, 1991, p.228).

\footnotetext{
${ }^{1}$ Docente do PPGE Mestrado em Educação da UFFS-Chapecó/SC E-mail: Claudecir.santos@ uffs.edu.br

${ }^{2}$ Mestranda do PPGE Mestrado em Educação da UFFS-Chapecó/SC E-mail: profestelamaris@ gmail.com

${ }^{3}$ Mestranda do PPGE Mestrado em Educação da UFFS-Chapecó/SC E-mail: neilacamerini@ hotmail.com
} 
Para nós, a observação de Lobato tem uma grande valia. Ou seja, se para as crianças um livro é todo um mundo, logo, compreender o contexto da criação desse livro e o seu conteúdo, é uma ação desencadeadora das diferentes visões de mundo possíveis a uma criança. Eis aí um dos motivos que tem nos impulsionado a conhecer melhor Monteiro Lobato e sua obra.

Frente ao cenário descrito, o presente texto se propõe a refletir sobre as implicâncias das obras de Monteiro Lobato e as formas pelas quais os profissionais da educação delas se utilizam, via livro didático, para explorar e aflorar, através da leitura, o imaginário e a criatividade das crianças com idade entre nove e dez anos, inseridas nos quartos e quintos anos do ensino fundamental.

Considerando a amplitude da obra lobatiana e a necessidade em manter o foco em nossa analise, o texto está organizado da seguinte forma: inicialmente, apresenta algumas informações sobre a vida de Monteiro Lobato, sobre sua literatura e seu desejo de "escrever para crianças", que inaugurou um novo momento histórico no Brasil. Novo, porque antes de Lobato, esse jeito de escrever para crianças se aproximava muito da literatura europeia, nem sempre condizente com a realidade das crianças brasileiras, realidade esta que pouco oportunizava o acesso aos mecanismos educacionais por parte da grande maioria dos brasileiros.

Em seguida, a partir de uma busca nos livros didáticos dos anos iniciais da educação básica, o texto expõe como a literatura lobatiana é apresentada nos exemplares analisados, ou seja, que configuração os textos lobatianos apresentam, sob que olhares são expressos as crianças, como são as suas adaptações, etc.

Sobre essa análise, é importante ressaltar que, por se tratar de uma literatura vasta e consideravelmente longa, optamos por observar apenas os livros dos quartos e quintos anos do ensino fundamental anos iniciais, disponibilizados pelo Ministério da Educação e Cultura, a toda rede pública de ensino. Esta análise se pautará em alguns critérios, entre eles, a diversidade dos textos, a importância que eles têm no contexto do livro em questão, a relevância dos aspectos relacionados às atividades de leitura e a compreensão da literatura lobatiana direcionada nestes exemplares.

Por fim, guiando-nos pela análise realizada, pretendemos "enxergar" as relações da obra de Monteiro Lobato com o momento histórico atual e compreender os desafios educacionais vivenciados na educação infantil. Esperamos que, ao longo desse percurso possamos pelo menos, motivar educadores e educadoras a se 
sensibilizarem quanto à influência da literatura infantil na construção de mundo das crianças. Em nosso entendimento, essa primeira ação amplia as possibilidades de investigação de um autor e sua obra, e Monteiro Lobato é merecedor disso.

\section{MONTEIRO LOBATO: BREVES OBSERVAÇÕES}

É indiscutível a influência de Monteiro Lobato na literatura infantil brasileira, justamente por isso, é importante saber quem foi esse autor para além de seus escritos mais conhecidos. Quem se debruçar sobre a vida de Monteiro lobato, saberá que ele também esteve as voltas com questões ligadas ao racismo e, também, ao fascismo. Alguns autores contemporâneos, aliás, afirmam que Lobato causou uma influência negativa nos bancos escolares ${ }^{4}$.

De acordo com esse pensamento, o "consumo" da obra lobatiana pelas crianças deveria ser repensado, pois os efeitos dos inúmeros termos não politicamente corretos que ele usa, poderia ter um sentido de apologia e/ou legitimação de diferentes tipos de preconceitos, entre eles o racial.

Trouxemos à baila este fato para chamar atenção dos profissionais da educação acerca deste assunto, entretanto, por conta das nossas intenções de pesquisa, neste texto, não nos ateremos a estas questões.

Monteiro Lobato viveu numa época modernista ${ }^{5}$ em que as mudanças e revoluções foram pontuais para o desenvolvimento da sociedade brasileira. No início da década de 1920, antes da emergência do chamado Estado Novo e logo após a Primeira Guerra Mundial, Lobato lança o livro Narizinho Arrebitado. Nessa época, livros infantis eram uma raridade, ou seja, Lobato foi um dos precursores de um estilo pouco comum em meio a produções literárias da época. Estilo esse que seguiu ao longo de mais de duas décadas, encerrando seus escritos no Brasil, em 1944, com o livro: Os doze trabalhos de Hércules. Este trabalho é resultado de narrativas feitas

\footnotetext{
${ }^{4}$ Sobre esse assunto, ver o Artigo: Monteiro Lobato e o Politicamente Correto. DADOS - Revista de Ciências Sociais , Rio de Janeiro, vol. 56, no 1, 2013, pp. 69 a 108. Disponível em: http://www.scielo.br/pdf/dados/v56n1/a04v56n1.pdf. Acesso em maio de 2016.

5 "Modernistas, de um lado, dando-nos o conteúdo estético do período; Monteiro Lobato, de outro, impondo uma práxis que, se é voltada para as letras, é igualmente com os olhos nos lucros. Mas, com Lobato, estamos no campo da ficção infantil, gênero que, se consistiu no ponto de encontro dessas vertentes, converteu-se, como se verá em seguida, numa das imagens dos contrastes culturais que perpassam a nação" (LAJOLO, 2007, p. 54)
} 
por Dona Benta sobre o Grécia Antiga. "A partir daquele ano, Lobato não publica livros novos no Brasil, e sim na Argentina, para onde se muda por algum tempo" (LAJOLO e ZILBERMAN, 2007, p. 45).

Lobato é considerado o pai da literatura infantil brasileira. Sua constante preocupação com a necessidade de oferecer ao seu público uma vasta impressão de como funciona a sociedade e suas ramificações. Entre suas intenções, está presente em suas obras a vontade de oportunizar as crianças um conhecimento de si e do mundo. Nesse sentido, a narrativa é o ponto marcante de seu estilo literário. Estilo considerado fundamental para o processo de formação da experiência coletiva, oportunizando o vínculo entre o passado e o presente e valorizando as diferentes aprendizagens.

Suas obras, recheadas de aventuras, deram vida a personagens e fatos que continuam vivos na memória dos tempos, seja através da história, tradição oral, lendas ou mitos. As histórias apresentam uma mistura de imaginário, aventura e conhecimentos da ciência. De acordo com Coelho (1991, p. 223), as obras lobatianas representam "o caminho criador que a literatura infantil estava necessitando. Rompe, pela raiz, com as convenções estereotipadas e abre as portas para as novas ideias e formas que o nosso século exigia". Isso significa dizer, que Lobato não estava apenas preocupado com seus livros, mas sim, em formar leitores, em produzir histórias contribuintes para com a infância brasileira. Em certa ocasião disse,

\footnotetext{
Quero fazer livros para as crianças morar. Não para ler e jogar fora, mas morar como eu morei no Robinson Crusoé-escreveu Lobato em carta escrita a Godofredo Rangel [...] morar no livro pela via da imaginação, este era o ideal do livro infantil do escritor (AZEVEDO apud LAJOLO 1996, p. 167).
}

De fato, muitos de seus leitores se viam e se veem morando em seus livros, tal sua capacidade de entreter as crianças em seu mundo imaginário. Nota-se isso, em diversas situações e momentos em que as crianças expressam o desejo de vivenciar as aventuras do Sítio do Pica Pau Amarelo.

Lobato recebeu inúmeras cartas de crianças pedindo para ser inseridas nas suas histórias e atendia a muitos dos pedidos incluindo, em cada nova história, novos personagens. Morar "no livro" torna-se então um sonho de inúmeras crianças brasileiras. Lobato faz parte de uma vasta literatura infantil que a partir do século XX começa a fazer parte da vida de muitas crianças. 
Através das histórias infantis com personagens tão ricos em sua existência, Monteiro Lobato inaugurou a possibilidade de rememorar e subverter a história e os fatos, oportunizando novas experiências e sugestivos meios de aprendizagem para quem gosta de apreciar uma boa leitura.

\section{LOBATO E OS LIVROS DIDÁTICOS}

Vivemos um momento histórico em que profissionais que trabalham com a infância e a juventude enfrentam desafios conflituosos relativos às condições sociais, econômicas e familiares dos estudantes que frequentam a educação básica. Tais conflitos se misturam com os processos de ensino e aprendizagem e, não raras vezes, "tumultuam" as ações pedagógicas e as intenções para com o desenvolvimento educacional e emocional das crianças.

É claro que, cada vez mais, aumentam as condições de estudo acerca de tudo o que rodeia o mundo infantil, mas isso não é suficiente para enfrentar as demandas que surgem para esta fase da vida de milhares de seres humano. Sobre este assunto, Sonia Kramer diz que,

Ao longo do século $X X$, cresceu o esforço pelo conhecimento da criança, em vários campos do conhecimento [...] sabemos que as visões sobre a infância são construídas social e historicamente. A inserção concreta das crianças varia com as formas de organização da sociedade (KRAMER, 2007, p. 14).

Sem dúvida, o esforço para com o conhecimento da criança simboliza uma evolução da humanidade, mas, como se sabe, o esforço para compreender o mundo infantil não é garantia de ações objetivas em relação à infância e suas necessidades. É preciso que o conhecimento se desenvolva acompanhado de ações práticas que atendam e respeitem as crianças.

Respeitar as crianças, porém, não se restringe em cuidados físicos. Estes, obviamente, são fundamentais para um desenvolvimento humano sadio, mas paralelo a eles estão os cuidados de ordem do intelecto. É aí que entra o debate sobre a qualidade da educação.

Neste sentido, em função da necessidade na qualidade da oferta da educação, muitas iniciativas têm sido tomadas ao longo das ultimas décadas, entre elas, a oferta e disponibilidade de materiais educativos necessários ao bom desempenho pedagógico e educativo. A esse respeito, citamos o Programa Nacional 
do Livro Didático (PNLD).

O PNLD teve início ainda em 1929. Lá se vão mais de 80 anos do programa que, de acordo com Ministério da Educação, o programa de distribuição de livros didáticos vem sendo aprimorado, adquirindo diferentes terminologias e formas de implemento, porém com o mesmo objetivo; o de oportunizar o acesso a estes exemplares a todos os estudantes da educação das redes públicas de ensino.

Sobre o PNLD, é pertinente saber a partir de que momento histórico o professor, enquanto parte fundamental do processo educativo passou a fazer parte diretamente da escolha dos livros didáticos da rede pública nacional de ensino.

Esta informação é importante, porque, entre outras condições, é possível dizer que, a partir do momento em que o professor passa a conhecer com que material está trabalhando, passa também a exercer a condição de sujeito autônomo acerca dos aspectos relativos ao conteúdo e ao currículo escolar.

Como o nosso objetivo não é fazer a análise histórica do livro didático, avançaremos para o ano de 2007, ano em que os anos iniciais do ensino fundamental passam a receber os livros didáticos de forma integral e sua distribuição abrange todas as disciplinas destas respectivas séries/anos.

Aqui, justifica-se o foco de nossa análise, pois buscamos conhecer e compreender como as narrativas de Monteiro Lobato são apresentadas nesses livros. É sempre bom lembrar que nosso interesse pelos livros didáticos dos quartos e quintos anos dos anos iniciais se deve ao fato de que estes leitores já possuem domínio da língua escrita e, portanto, conseguem estabelecer as relações entre tais leituras.

Para início de nosso estudo, consideraremos um total de quatro exemplares de Língua Portuguesa dos quartos anos do ensino fundamental e três exemplares de Língua Portuguesa dos quintos anos, também dos anos iniciais do ensino fundamental. Estes exemplares, além de estarem disponíveis em diversas escolas, também podem ser conhecidos através de suas resenhas, disponíveis na página do PNLD do Ministério da Educação.

\subsection{OS EXEMPLARES DOS QUARTOS ANOS.}

No exemplar I, ano de 2004, da coleção Vitória Régia, editora Ibep, observamos que os textos de Monteiro Lobato se apresentam na especificidade de 
fábulas. Quanto às atividades de interpretação, aparentam ser indutivas e diretas e raramente oportunizam diferentes direcionamentos. Nele encontramos, na página 30 (trinta), um breve embasamento teórico em que cita a obra do Sítio do Pica-pau Amarelo fazendo menção a Monteiro Lobato. Na página vinte e seis, das atividades direcionadas aos alunos, encontramos a fábula $O$ leão $e$ o ratinho da editora brasiliense.

No exemplar II, ano de 2008, da editora Atual, não foram identificadas as obras de Monteiro Lobato.

No exemplar III, ano de 2012, da coleção Viraver, editora Scipione, na unidade dez, página duzentos e dez, o livro traz a biografia e fotos do autor numa linguagem muito acessível. Há um capítulo somente para as obras de Monteiro Lobato e sua biografia, exigindo dos professores um conhecimento prévio sobre o assunto que tratam das histórias do Sítio do Pica-pau Amarelo e reúnem diferentes contos no próprio texto inicial do capítulo. Também no início do capítulo há uma prévia interessante que procura levar ao conhecimento dos leitores, quem é Monteiro Lobato. Quanto às atividades de interpretação, seguem basicamente os mesmos padrões clássicos dos demais apostilados. Também são introduzidas questões gramaticais, e, soma-se a isso, o teatro como forma de gênero textual.

O exemplar IV, ano de 2011, coleção Aprender Juntos, editora Sm, na página cento e noventa e seis e a seguir, traz uma narrativa de Monteiro Lobato que trata da formação de opinião e da importância de não se deixar levar pelo pensamento alheio. As páginas subsequentes trazem atividades de interpretação de texto numa perspectiva mais habitual.

As possibilidades oportunizadas aos professores e alunos analisadas nestes exemplares nos fornecem subsídios para muitas interpretações. Enquanto objeto de estudo neste momento observamos que, entre vários exemplares selecionados, muitos nem chegam a mencionar as obras e narrativas de Monteiro Lobato, enquanto outros dedicam um bom espaço para análise. Alguns se remetem a Monteiro Lobato como o pai da literatura infantil no Brasil, enquanto outros apenas trazem breves fábulas e narrativas escritas pelo autor.

\subsection{OS EXEMPLARES DOS QUINTOS ANOS}

No exemplar I, ano de 2008, da coleção Português Linguagens, editora 
Atual, não foram observadas narrativas, fábulas ou poemas de Monteiro Lobato.

No exemplar II, ano de 2012, da coleção A Escola é Nossa, editora Scipione, na página cento e dezesseis, Monteiro Lobato se faz presente com o texto $A$ formiga boa, inspirado na fábula $A$ cigarra e as Formigas, da qual mantém o início e modifica o final. $O$ livro traz apenas esta fábula e pouco cita ou relata sobre o autor.

No exemplar III, ano de 2009, da coleção Língua Portuguesa, editora Scipione, o livro traz um texto direcionado às crianças, em que Monteiro Lobato apresenta a ideia da formiga boa e da formiga má e faz alusão aos personagens do Sítio do Pica-pau Amarelo, inspirado na fábula de Esopo. Traz também a biografia do autor e cita algumas de suas obras a título de informação na página duzentos e nove.

\section{LOBATO E O CONTEXTO ATUAL}

Após as leituras sobre Lobato e sua obra que caracterizaram um forte marco na literatura brasileira, até o presente momento, é possível perceber que Lobato "foi feliz" ao permitir que sua ideia inicial de escrever para adultos fosse substituída pela vontade de escrever para crianças. Vontade essa registrada em diferentes falas em que Lobato expressa o mais puro desejo de escrever para crianças, especialmente em uma época em que o Brasil passava por diversas mudanças de ordem social, política e econômica. Em decorrência disso, surgem significativas mudanças educacionais que abrem espaço para novas ideias e novos desafios aos educadores.

O entusiasmo com as obras de Monteiro Lobato tem impulsionado nossas buscas por histórias infantis presentes nos livros didáticos e as formas com que são narradas, mas isso ainda é pouco para que possamos "enxergar" as relações da obra de Monteiro Lobato com o momento histórico atual e compreender os desafios educacionais vivenciados na educação infantil. Entretanto, as pesquisas estão mostrando que a escola, cada vez mais, precisa aprender a ser um lugar de acolhimento à diversidade. E como tal, precisa estar preparada para dar oportunidade ao germe da diversidade. Nesse sentido, a literatura infantil, infantil apresenta-se como uma possibilidade ímpar ao futuro da escola.

A obra de Monteiro Lobato continua sendo atual em diversos aspectos e sua influência na literatura infantil brasileira é perceptível através da continuidade 
das suas histórias e da lembrança de seus personagens. Porém, mais importante que isso, interessa saber as semelhanças entre o contexto histórico em que Lobato escreveu e o momento atual. Sobre esta análise, porém, o espaço não nos permite ampliá-la. Por isso, por ora, entendemos que precisamos ressaltar o que, a nosso ver, sintetiza esta relação, ou seja; a literatura infantil precisa identificar as falas recolhidas $^{6}$ e, da altura das crianças, narrar experiências onde a sabedoria se transforma no dispositivo que permite as crianças construírem lugares onde possam se movimentar, criar e recriar um novo mundo a partir do que está a sua volta.

Lobato teve êxito neste aspecto e com seu propósito em escrever para crianças. Mas as crianças da época de Monteiro Lobato não tinham diante de si o que as crianças do século XXI tem. Por essa razão, entendemos que se faz necessário dialogar com os sonhos das crianças, a partir da "altura" em que elas se encontram, como fez Lobato, mas não podemos esquecer que estamos sentados nos ombros do passado e criando as bases para um mundo onde nossas crianças conhecerão o que fizemos e criarão o que outras irão conhecer.

\section{CONSIDERAÇÕES FINAIS}

Nesta rápida análise sobre Monteiro Lobato e a literatura na escola verificamos que a presença das obras de Monteiro Lobato, através dos livros didáticos dos quartos e quintos anos do ensino fundamental, é muito restrita. Além disso, notamos também que os livros que trazem sua literatura focam mais em atividades de repetição do tipo pergunta e resposta, do que das histórias por ele criadas, deixando, com isso, de dar a devida importância às obras lobatianas.

No entanto, nossas vivências enquanto professores na área da educação infantil e anos iniciais retratam uma realidade próxima àquela sonhada por Lobato, 0 desejo de morar nos livros, manifesto pelas crianças ao se depararem com suas obras, tal seu encantamento e capacidade envolve-las. A presença destas histórias escritas há tanto tempo, mas tão atuais, movem pais e educadores para a

\footnotetext{
${ }^{6}$ Em referência a boneca Emília que, ao receber uma pílula, falou tanto que Narizinho, atordoada, disse ao doutor que era melhor fazê-la vomitar aquela pílula e engolir outra mais fraca. - Não é preciso - explicou o grande médico. - Ela que fale até cansar. Depois de algumas horas de falação, sossega e fica como toda gente. Isto é "fala recolhida", que tem de ser botada para fora.
} 
possibilidade de motivar nossas crianças ao ato de ler, de viver as histórias infantis e de rememorar as fantasias e realidades presentes nestas obras.

A Monteiro Lobato coube a nobre tarefa de instaurar o divisor de águas entre o Brasil de ontem e o Brasil de hoje. Ao romper com o estilo clássico europeu, causa enorme alegria às crianças de sua época e as de hoje, abrindo caminho para as novas demandas e mostrando que há diferentes maneiras de fazer as crianças morarem nos livros com extensa aceitação por parte do público infantil e porque não dizer, dos adultos. Seus livros foram traduzidos para vários países como Alemanha, Argentina, Espanha, França e Síria, razão de sua grandiosa relevância.

Contudo, está cada vez mais claro que, conheceremos suas obras mais de perto, assim como o seu alcance literário, na medida em que avançarmos na pesquisa. Eis a razão de se aproveitar momentos importantes, como é o caso da escrita desse ensaio, para socializar os estudos em andamento.

\section{REFERÊNCIAS}

BRASIL. Lei n. 11.274, de 06 de fevereiro de 2006. Altera a redação dos arts. 29, 30, 32 e 87 da Lei no 9.394, de 20 de dezembro de 1996, que estabelece as diretrizes e bases da educação nacional, dispondo sobre a duração de 9 (nove) anos para o ensino fundamental, com matrícula obrigatória a partir dos 6 (seis) anos de idade. Diário Oficial da União, DF, 06 Fev 2006.

Lei n. 9.394/96 de 20 de dezembro de 1996. Para dispor sobre o ensino fundamental obrigatório, com duração de 9 (nove) anos, gratuito na escola pública, iniciando-se aos 6 (seis) anos de idade, terá por objetivo a formação básica do cidadão. Diário Oficial da União, Brasília, DF, 20 de dez. 1996.

COELHO, N. N. Panorama histórico da literatura infanto/juvenil. São Paulo: Ática, 1991.

JÚNIOR, J. F.; NASCIMENTO, L. F.; EINSENBERG, Z. W. Monteiro Lobato e o Politicamente Correto. Revista de Ciências Sociais, Rio de Janeiro, vol. 56, no 1, 2013, pp. 69 a 108. Disponível em: <http://www.scielo.br/pdf/dados/v56n1/a04v56n1.pdf>. Acesso em: 05 Maio 2016.

KRAMER, S; LEITE, M. I. (Orgs.) Infância e educação infantil. Campinas: Papirus, 2007. 
LAJOLO, M; ZILBERMAN, R. A formação da leitura no Brasil. São Paulo: Ática, 1996.

M. O regionalismo lobatiano na contramão do Modernismo. Remate de Males. Campinas, 1987.

M; ZILBERMAN, R. Literatura infantil brasileira: história \& histórias. São Paulo: Ática, ed.6모 2007.

MINISTÉRIO DA EDUCAÇÃO E CULTURA (MEC). Plano Nacional do Livro Didático. 2016, Brasil. Disponível em:<http://www.fnde.gov.br/programas/livrodidatico/livro-didatico-historico>. Acesso em: 04 Abril 2016. 